\title{
Determination of Enalapril maleate from tablets using a new HPLC method
}

\author{
Simona GHERMAN, Daniela ZAVASTIN*, Adrian ŞPAC, and Alina Diana PANAINTE \\ “Grigore T. Popa" University of Medicine and Pharmacy, Faculty of Pharmacy, 16 University Str., 700115, Iasi, \\ România
}

\begin{abstract}
For the determination of enalapril maleate in tablets a new, simple and economical HPLC method was developed and fully validated. Chromatographic separation was achieved on Hewlett Zorbax SB-C 18 (150 x 4.6 mm, 5 $\mu \mathrm{m})$ column and the mobile phase consisted of acetonitrile: $0.025 \mathrm{M}$ phosphate buffer adjusted to $\mathrm{pH} 3(70: 30 \mathrm{v} / \mathrm{v})$ pumped at a flow rate $0.8 \mathrm{~mL} / \mathrm{min}$ and UV-detection was performed at $210 \mathrm{~nm}$. The proposed method was validated according to ICH guidelines (linearity, limit of detection, limit of quantification, precision, accuracy, recovery and system suitability). The total run time was less than $3 \mathrm{~min}$ and the retention time for Enalapril maleate was $2.3 \mathrm{~min}$. The calibration graph was linear in the concentration range between $10-100 \mu \mathrm{g} / \mathrm{mL}$ with the correlation coefficient $\mathrm{r}^{2}=0.9998$. The developed and validated method was successfully applied to determine the Enalapril maleate in tablets. Therefore, this method proved to be sensitive, specific and reproducible and can be applied for routine analysis of enalapril maleate from pharmaceutical formulation due to its simplicity of application.
\end{abstract}

Keywords: Enalapril maleate; HPLC; method validation; limit of detection.

\section{Introduction}

Enalapril maleate is an angiotensin converting enzyme inhibitor (ACE) used in the treatment and prevention of symptomatic heart failure in patient with asymptomatic left ventricular dysfunction. This prodrug is rapidly absorbed after oral administration and through deesterification is converted into its active form - enaprilat [1-3]. Enalapril maleate is chemically described as: (1[N-[(S)-1-carboxy-3-phenylpropyl]-L-alanyl]-L-proline 1 '-ethyl ester, maleate (1:1)) [3].

The therapeutic importance of Enalapril maleate has led to its increasing use and thus to the development of numerous methods of determining this drug. The determination of the Enalapril maleate, alone or in combination with other drugs, has been carried out by various analytical techniques, such as spectrophotometric methods, which, in most cases, involves extraction with organic solvents [4, 5] and many reagents [6-9], or by high performance liquid chromatography (HPLC), which it is the most common practical technique for the determination of this drug. HPLC methods have the advantage of determining the drug in a much shorter time than other analytical methods, and the degradation products do not interfere [10-12].

The aim of this study is to develop a fast, selective, accurate, precise and sensitive RP-HPLC method for quantitative determination of Enalapril. After development and validation, the method was applied for the estimation of Enalapril maleate from tablets. The present HPLC method was validated in accordance with the guidelines presented at the International Conference on Harmonization (ICH) [13]. The developed method is economically viable and can be used to Enalapril maleate dosing for the routine analyzes in laboratories.

\section{Experimental}

\subsection{Instrumentation and chromatographic conditions} Method development and validation were carried out on an Agilent Technologies 1200 Series HPLC System with a Diode Array Detector. In order to establish the best chromatographic conditions, several columns with the same stationary phases, but different dimensions and particle size were tested: Agilent Zorbax SB-C18 (100x3 mm, $5 \mu \mathrm{m})$, Hewlett Zorbax SB-C18 (150x4.6 $\mathrm{mm}, 5 \mu \mathrm{m})$ and Phenomenex C-18 (250x4.6 mm, $5 \mu \mathrm{m})$.

The chromatographic separation of Enalapril maleate was achieved using a Hewlett Zorbax SB-C 18 $(150 \times 4.6 \mathrm{~mm}, 5 \mu \mathrm{m})$ column purchased from Agilent; this column was used at all work stages (development, validation and applications on tablets). The chromatographic assay was performed at $25^{\circ} \mathrm{C}$ using a $20 \mu \mathrm{L}$ sample, at a flow rate of $0.8 \mathrm{~mL} / \mathrm{min}$ with injection volume of $50 \mu \mathrm{L}$. The effluent was monitored spectrophotometrically at $210 \mathrm{~nm}$.

Other used apparatuses were analytical balance Partner AS 110/C/1 with precision $0.1 \mathrm{mg}, \mathrm{pH}$ conductivity meter InoLab Level 1 for rapidly and reliably measurements of $\mathrm{pH}$ values and a Cole Parmer ultrasonic bath.

\subsection{Chemicals and reagents}

All chemicals, the solvents and other materials were HPLC grade provided by Sigma Aldrich and Fluka. The Enalapril maleate (purity $100.4 \%$ ) reference substance was supplied from Zhejiang Huahai Pharmaceuticals Co., China and maleic acid was provided from Sigma Aldrich. Pharmaceutical formulations of 10 and $20 \mathrm{mg}$ Enalapril maleate tablets were acquired from local pharmacies.

\footnotetext{
* Corresponding author. E-mail addresses: daniela.zavastin@umfiasi.ro (Daniela Zavastin)
} 


\subsection{Preparation of mobile phase}

The mobile phase was a mixture of potassium dihydrogen phosphate buffer solution $(0.025 \mathrm{M}$, adjusted at $\mathrm{pH} 3$ with orthophosphoric acid) [14] and acetonitrile $(30: 70 \mathrm{v} / \mathrm{v})$. The mixture was filtered and degassed through $0.45 \mu \mathrm{m}$ membrane filter paper.

\subsection{Preparation of solutions}

Stock standard solution: $10 \mathrm{mg}$ of Enalapril maleate was dissolved in mobile phase and diluted to $100 \mathrm{~mL}$ with the same solvent $(100 \mu \mathrm{g} / \mathrm{mL})$. The working standard solutions were obtained by dilution with mobile phase.

Placebo solution: $10 \mathrm{mg}$ of each excipient (sodium hydrogen carbonate, lactose monohydrate, corn starch, red iron oxide, magnesium stearate and talcum) was shaken at ultrasonic bath with $100 \mathrm{~mL}$ of mobile phase then was centrifuged. The clear supernatant liquid was filtered through a $0.45 \mu \mathrm{m}$ membrane filter.

Maleic acid stock solution: $10 \mathrm{mg}$ of maleic acid was dissolved in mobile phase and diluted to $100 \mathrm{~mL}$ with the same solvent $(100 \mu \mathrm{g} / \mathrm{mL})$.

\subsection{Analysis of dosage form}

In order to verify the validity of the developed method, a series of tablets with a different content of Enalapril maleate were analyzed. They were studied two types of tablets, with a content of Enalapril of $10 \mathrm{mg}$ and respectively $20 \mathrm{mg}$. For both types of tablets, twenty Enalapril maleate tablets were accurately weighed, crushed and finely powdered.

The equivalent amounts of powder which corresponds to $10 \mathrm{mg}$ and $20 \mathrm{mg}$ of Enalapril maleate $(0.1687 \mathrm{~g}$ and $0.1649 \mathrm{~g})$ was transferred to $25 \mathrm{~mL}$ volumetric flask and dissolved in $20 \mathrm{~mL}$ mobile phase at ultrasonic bath for $30 \mathrm{~min}$. The solutions were filtered through $0.45 \mu \mathrm{m}$ membrane in order to separate the excipients and the volume was made up with mobile phase. The working solutions, with a concentration of 20 $\mu \mathrm{g} / \mathrm{mL}$, were obtained by dilution with the same mobile phase.

\subsection{Method development and validation}

The HPLC method was develop with the aim to have an effective method for the estimation of Enalapril maleate in tablet dosage forms. The preliminary tests have been made in order to select the optimum chromatographic conditions. In order to obtain the most effective method, first, three different columns were study as a stationary phase, then different rations of mobile phase and different flow rates were tested. The ICH guideline was used to validate the developed HPLC method following the parameters specified by it [13, 15-17].

2.6.1. Specificity. Specificity is the ability to measure the analyte with accuracy and without interference from placebo. The specificity of the method was determined by injecting placebo, standard and sample solutions and recording the chromatograms using the described method.

2.6.2. System suitability. In order to evaluate the system suitability three replicates of the standard solution containing Enalapril maleate were analyzed. The reproducibility of the chromatographic system was determined by calculating the repeatability of peak response (RSD), theoretical plate number $(\mathrm{N})$, capacity factor $\left(\mathrm{k}^{\prime}\right)$ and symmetry factor $(\mathrm{S})$ [18].

2.6.3. Linearity, detection and quantification limits. A concentration domain between $1-100 \mu \mathrm{g} / \mathrm{mL}$ was used to assess the method linearity and the calibration curve was obtained using linear regression.

In accordance with the International Conference on the Harmonization guideline [13] the detection limit (DL) and quantification limit (QL) were estimated based on standard deviation of the intercept from regression equation (SD).

2.6.4. Precision and accuracy. The intra-day and interday precision of the method were carried out immediately after preparation of the samples and in three different days. Standard deviation (SD) and relative standard deviation (RSD\%) for the active compound were calculated. The accuracy was evaluated through recovery.

Recovery studies were performed in order to evaluate the accuracy of the proposed method. It was realized by adding to pre-analyzed sample a known quantity of pure drug. Then the sample was reanalyzed and the percent recovery was reported.

2.6.5. Ruggedness and robustness. Evaluation of robustness was achieved by making some small deliberate changes in the method parameters. The effects of modifying flow rate $(0.05 \mathrm{~mL} / \mathrm{min})$ and column temperature $\left( \pm 0.5^{\circ} \mathrm{C}\right)$ on the peak area were studied $[18,19]$.

\subsection{Analysis of Enalapril maleate in tablet formulation}

The developed method was applied to the study of two types of tablets with different content in Enalapril maleate and the amount of active substance in the samples was calculated.

\subsection{Statistical analysis}

All determinations were performed in triplicate. The results were expressed as mean value \pm standard deviation being considered as statistically significant at $p<0.05$. Student's t-test at $95 \%$ confidence level was performed using SPSS 18.0 statistical software.

\section{Results and discussion}

\subsection{Method development and optimization}

A fast and easy to use quantitative and qualitative HPLC method has been developed for Enalapril maleate analysis in tablets. To obtain the best chromatographic conditions, various parameters have been varied, such as: the stationary phase, the mobile phase composition and flow rate. The first step was establishing the type of chromatographic column. Thereby, were tested out three columns by using the same concentration of Enalapril maleate, mobile phase and flow. The results are summarized in Table 1 from which it is noticed that the best results were achieved with Hewlett Zorbax column. 
Table 1. Retention time ( $\mathrm{t}_{\mathrm{r}}$ ) on different columns

\begin{tabular}{|c|c|c|c|c|c|}
\hline No. & Column & $\begin{array}{c}\text { Concentration EM } \\
(\mu \mathrm{g} / \mathrm{mL})\end{array}$ & Mobile phase & $\begin{array}{c}\text { Flow } \\
(\mathrm{mL} / \mathrm{min})\end{array}$ & $\mathbf{t}_{\mathbf{r}}(\min )$ \\
\hline 1. & $\begin{array}{l}\text { Agilent Zorbax SB-C18 } \\
(100 \times 3 \mathrm{~mm}, 5 \mu \mathrm{m})\end{array}$ & 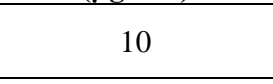 & \multirow{3}{*}{$\begin{array}{c}\mathrm{CH}_{3} \mathrm{CN}: \mathrm{KH}_{2} \mathrm{PO}_{4}(\mathrm{pH} \\
\left.=3.0 \text { using } \mathrm{H}_{3} \mathrm{PO}_{4}\right) \\
(30: 70)\end{array}$} & 1 & 8.9 \\
\hline 2. & $\begin{array}{c}\text { Hewlett Zorbax SB-C18 } \\
(150 \times 4.6 \mathrm{~mm}, 5 \mu \mathrm{m})\end{array}$ & 10 & & 1 & 5.1 \\
\hline 3. & $\begin{array}{l}\text { Phenomenex C-18 } \\
(250 \times 4,6 \mathrm{~mm}, 5 \mu \mathrm{m})\end{array}$ & 10 & & 1 & $\begin{array}{c}7.2 \text { asymmetric } \\
\text { peak }\end{array}$ \\
\hline
\end{tabular}

Varying the mobile phase led to considerable changes of the chromatographic parameters, like peak symmetry and retention time. Because the polar mobile phase has a profound effect on the separation of polar drug molecules, different ratios of acetonitrile and phosphate buffer solution ( $\mathrm{pH} 3$ ) were used. The best separations were obtained with 70:30 (v/v) mobile phase. Then the influence of the mobile phase flow on peak normalization was studied, and the optimum flow rate was $0.8 \mathrm{~mL} / \mathrm{min}$ (Fig. 1).

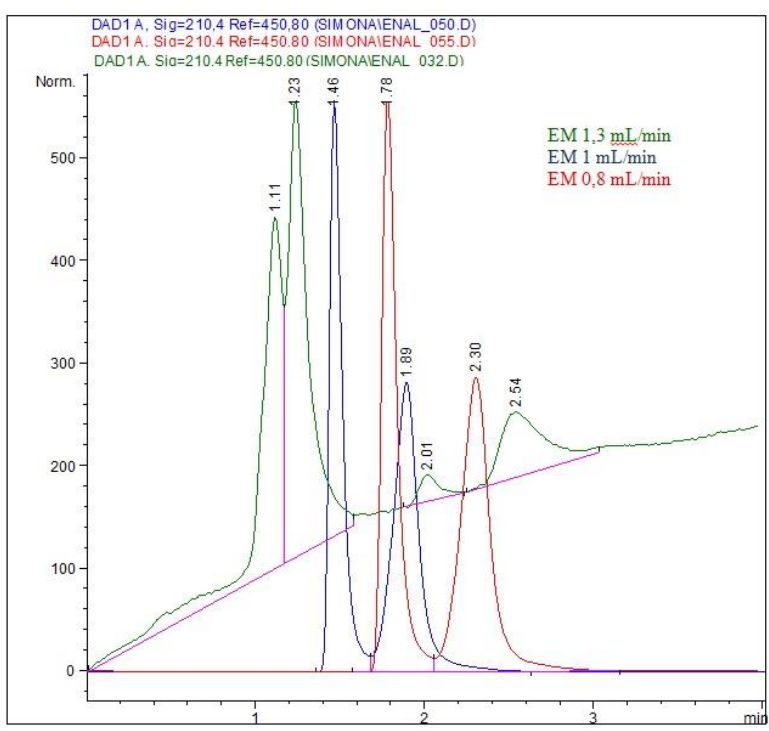

Figure 1. The flow rate study

The UV spectrum of drug was recorded at the wavelength range from 200 to $400 \mathrm{~nm}$ and was observed that detector responded well at wavelength $210 \mathrm{~nm}$. This value was considered satisfactory, permitting the detection of Enalapril maleate with adequate sensitivity (Fig. 2).

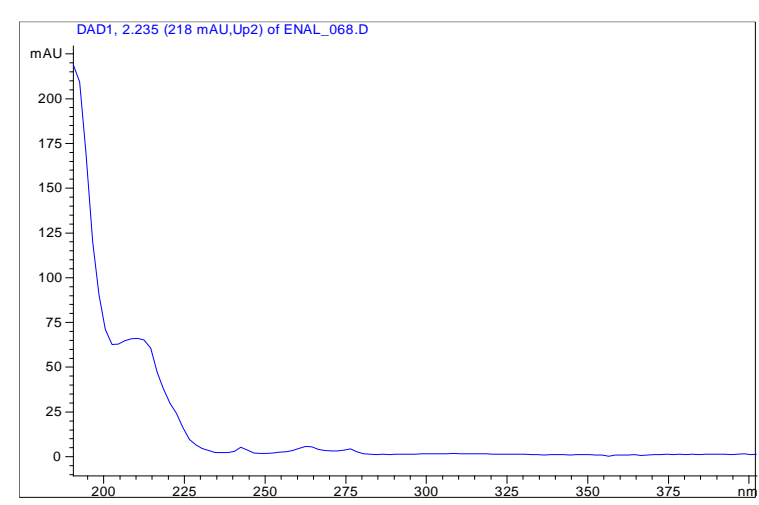

Figure 2. The UV spectra of Enalapril maleate

After studying these method parameters, it was established by repeated injection of the maleic acid and Enalapril maleate solutions, that the elution times are 1.7 min and respectively $2.3 \mathrm{~min}$. The results are shown in the chromatogram presented in Fig. 3.

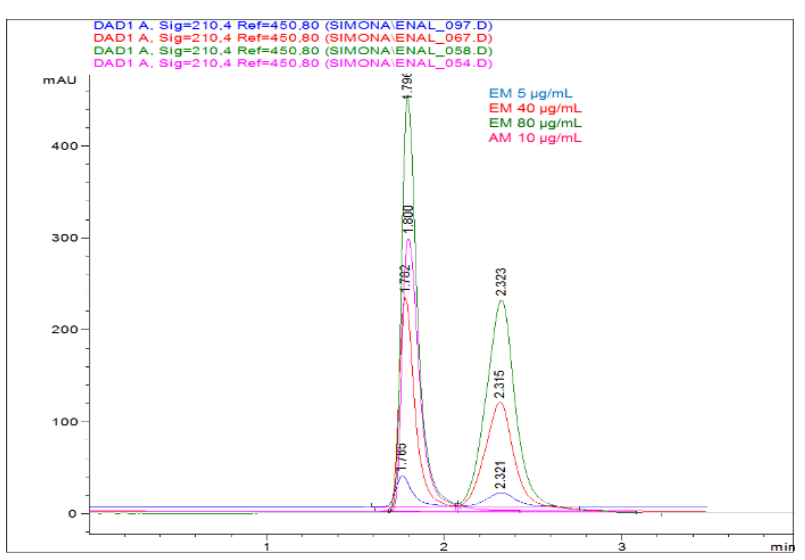

Figure 3. Retention time

\subsection{Method validation}

3.2.1. Specificity. Specificity of the method was tested by comparing the response of standard, sample and placebo solutions. From Fig. 4 we can observe that the proposed method is able to separate a signal for Enalapril maleate and also that there is no interference of excipients suggesting the selectivity of it. 


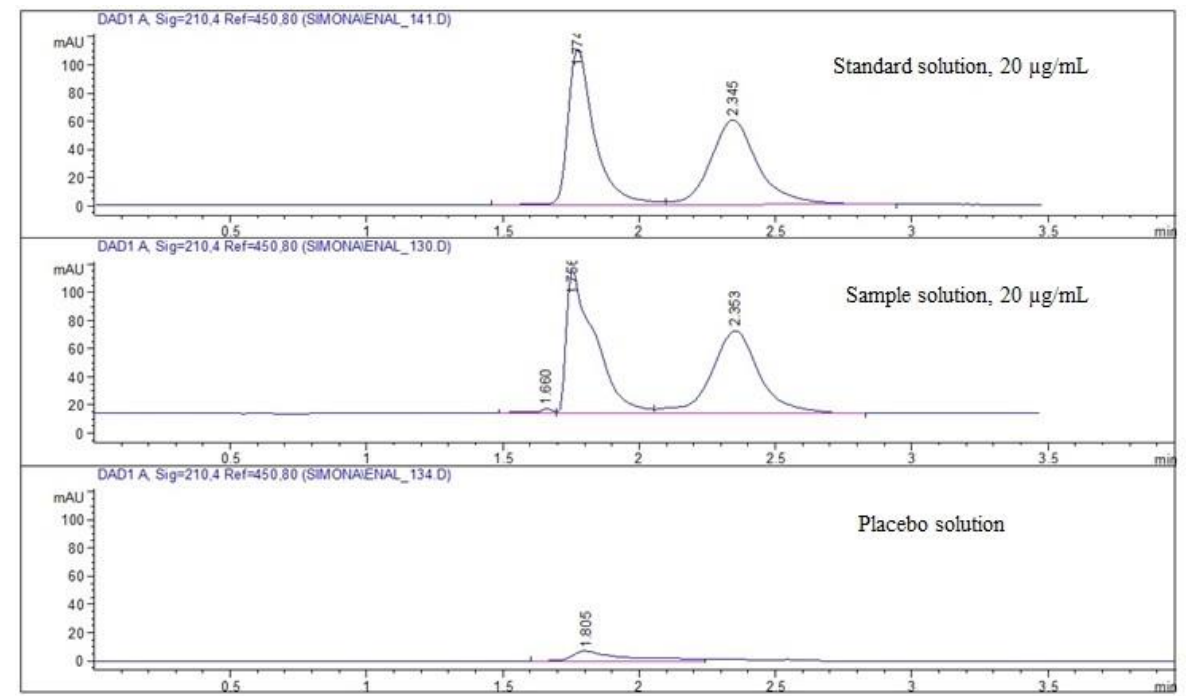

Figure 4. Chromatograms for the standard $(20 \mu \mathrm{g} / \mathrm{mL})$, sample $(20 \mu \mathrm{g} / \mathrm{mL})$ and placebo $(20 \mu \mathrm{g} / \mathrm{mL})$

3.2.2. System suitability. The results of the system suitability test were all within acceptable limits [20]. The symmetry factor was 1.72 , the theoretical plates were 6400 and the capacity factor was 5.02. Reference values for HPLC system suitability parameters are $\mathrm{k}^{\prime} \geq$ $2, \mathrm{~S} \leq 2$ and $\mathrm{N} \geq 2,000$.

3.2.3. Linearity and detection limit. Good linear regression $\left(R^{2}=0.9998 \pm 0.0001\right)$ was obtained in the
Enalapril maleate concentration range of $1-100 \mu \mathrm{g} / \mathrm{mL}$ The developed method was found to be very sensitive with values for DL and QL of $0.31 \mu \mathrm{g} / \mathrm{mL}$ and respectively, $0.94 \mu \mathrm{g} / \mathrm{mL}$.

3.2.4. Precision and accuracy. Three different concentrations $(15,20$ and $25 \mu \mathrm{g} / \mathrm{mL})$ were tested in order to establish method precision and accuracy (Table 2).

Table 2. Intra-day, inter-day precision and accuracy

\begin{tabular}{|c|c|c|c|c|c|c|c|c|c|}
\hline \multirow{2}{*}{$\begin{array}{c}c_{\text {th }} \\
(\mu \mathrm{g} / \mathrm{mL})\end{array}$} & \multicolumn{3}{|c|}{ Intra-day precision } & \multicolumn{3}{|c|}{ Inter-day precision } & \multicolumn{3}{|c|}{ Accuracy } \\
\hline & $\begin{array}{c}c_{\exp } \\
(\mu \mathrm{g} / \mathbf{m L})\end{array}$ & $\%$ recovery & $\begin{array}{c}\text { Statistical } \\
\text { data }\end{array}$ & $\begin{array}{c}c_{\exp } \\
(\mu \mathrm{g} / \mathrm{mL})\end{array}$ & $\%$ recovery & Statistical data & $\begin{array}{c}c_{\exp } \\
(\mu \mathrm{g} / \mathbf{m L})\end{array}$ & $\%$ recovery & $\begin{array}{c}\text { Statistical } \\
\text { data }\end{array}$ \\
\hline \multirow{3}{*}{15} & 14,88 & 99,23 & AV: 14.89 & 14.80 & 98.68 & \multirow{3}{*}{$\begin{array}{c}\text { AV: } 14.81 \\
\text { SD: } 0.18 \\
\text { RSD: } 1.18\end{array}$} & 14.65 & 97.66 & \multirow{3}{*}{$\begin{array}{c}\text { AV: } 14.79 \\
\text { SD: } 0.17 \\
\text { RSD: } 1.13\end{array}$} \\
\hline & 15,07 & 100,49 & SD: 0.22 & 14.99 & 99.94 & & 14.97 & 99.82 & \\
\hline & 14,63 & 97,53 & RSD: 1.48 & 14.64 & 97.61 & & 14.74 & 98.24 & \\
\hline \multirow{3}{*}{20} & 20,30 & 101,48 & AV: 20.27 & 20.43 & 102.17 & \multirow{3}{*}{$\begin{array}{c}\text { AV: } 20.17 \\
\text { SD: } 0.28 \\
\text { RSD: } 1.37\end{array}$} & 20.40 & 101.99 & \multirow{3}{*}{$\begin{array}{c}\text { AV: } 20.17 \\
\text { SD: } 0.30 \\
\text { RSD: } 1.51\end{array}$} \\
\hline & 20,01 & 100,07 & SD: 0.24 & 20.19 & 100.95 & & 19.83 & 99.14 & \\
\hline & 20,51 & 102,53 & RSD: 1.20 & 19.89 & 99.43 & & 20.30 & 101.49 & \\
\hline \multirow{3}{*}{25} & 25,20 & 100,80 & AV: 24.95 & 24.59 & 98.35 & \multirow{3}{*}{$\begin{array}{c}\text { AV: } 24.93 \\
\text { SD: } 0.34 \\
\text { RSD: } 1.35\end{array}$} & 24.85 & 99.39 & \multirow{3}{*}{$\begin{array}{r}\text { AV: } 24.87 \\
\text { SD: } 0.19 \\
\text { RSD: } 0.77\end{array}$} \\
\hline & 24,80 & 99,21 & SD: 0.20 & 25.26 & 101.03 & & 24.69 & 98.77 & \\
\hline & 25,07 & 100,27 & RSD: 0.81 & 24.96 & 99.84 & & 25.07 & 100.29 & \\
\hline
\end{tabular}

$\mathrm{c}_{\mathrm{th}}$ - theoretical concentration; $\mathrm{c}_{\exp }$ - experimental concentration; AV - average; SD - standard deviation; RSD \% - relative standard deviation

The intra- and inter-day precisions of measurements were lower than the required criteria; the recovery variation was between 97.53 and $102.53 \%$. The RSD value in precision and accuracy was less than $2 \%$ indicating that the proposed method is precise and accurate.
3.2.5. Ruggedness and robustness. The results obtained for ruggedness and robustness are presented in Table 3. The values are within the acceptable limits and these demonstrate that the developed method is rugged and robust.

Table 3. Ruggedness and robustness

\begin{tabular}{|c|c|c|c|c|c|}
\hline $\begin{array}{c}c_{\text {th }} \\
(\mu \mathrm{g} / \mathrm{mL})\end{array}$ & $\begin{array}{l}\text { Flow rate } \\
(\mathrm{mL} / \mathrm{min})\end{array}$ & $\begin{array}{c}\text { Temperature } \\
\left({ }^{\circ} \mathrm{C}\right)\end{array}$ & Average area & $\begin{array}{c}c_{\exp } \\
(\mu \mathrm{g} / \mathrm{mL})\end{array}$ & $\begin{array}{c}\text { Recovery } \\
(\%)\end{array}$ \\
\hline \multirow[t]{3}{*}{25} & 0.75 & 20 & 898 & 24.69 & 98.75 \\
\hline & 0.8 & 25 & 920 & 25.32 & 101.27 \\
\hline & 0.85 & 30 & 935 & 25.72 & 102.90 \\
\hline \multirow[t]{3}{*}{50} & 0.75 & 20 & 1786 & 49.36 & 98.72 \\
\hline & 0.8 & 25 & 1785 & 49.33 & 98.67 \\
\hline & 0.85 & 30 & 1839 & 50.82 & 101.65 \\
\hline \multirow[t]{3}{*}{75} & 0.75 & 20 & 2653 & 73.43 & 97.90 \\
\hline & 0.8 & 25 & 2713 & 75.09 & 100.12 \\
\hline & 0.85 & 30 & 2763 & 76.48 & 101.97 \\
\hline
\end{tabular}

3.2.6. Stability. To test Enalapril maleate stability in solution of mobile phase, a number of three replicates with $20 \mu \mathrm{g} / \mathrm{mL}$ concentration, were kept at room temperature for $48 \mathrm{~h}$. The obtained results are summarized in Table 4 and showed that Enalapril maleate is found to be stable in solution at room temperature $(\mathrm{RSD}=0.89 \%)$. 
Table 4. Analyte stability in solution at room temperature

\begin{tabular}{|c|c|c|}
\hline $\begin{array}{c}\text { Time } \\
\text { (h) }\end{array}$ & Peak area & Statistical data \\
\hline 0 & 737.5 & \multirow{7}{*}{$\begin{array}{c}\text { Average: } 735.44 \\
\text { SD: } 6.58 \\
\text { RSD: } 0.89 \%\end{array}$} \\
\hline 1 & 746.9 & \\
\hline 2 & 739.8 & \\
\hline 4 & 734.5 & \\
\hline 6 & 728.7 & \\
\hline 24 & 732.2 & \\
\hline 48 & 728.5 & \\
\hline
\end{tabular}

\subsection{Recovery of Enalapril maleate tablet assay}

The tablets with Enalapril maleate in different concentrations were prepared as described earlier and were analyzed in order to check the applicability of the developed HPLC method. In Table 5 it can be observed reasonable recovery and RSD\% values.

Table 5. Recovery results of Enalapril maleate tablet assay

\begin{tabular}{|c|c|c|c|}
\hline $\begin{array}{c}\text { Label } \\
\text { claim, } \\
(\mathbf{m g})\end{array}$ & $\begin{array}{c}\text { Amount } \\
\text { found; } \\
\text { mean } \pm \text { SD } \\
(\mathbf{m g})\end{array}$ & $\begin{array}{c}\text { Recovery } \\
(\mathbf{\%})\end{array}$ & $\begin{array}{c}\text { RSD } \\
(\mathbf{\%})\end{array}$ \\
\hline $\mathbf{1 0}$ & $9.98 \pm 0.17$ & 99.83 & 1.63 \\
\hline $\mathbf{2 0}$ & $20.07 \pm 0.26$ & 100.35 & 1.27 \\
\hline
\end{tabular}

\section{Conclusions}

The proposed HPLC method was successfully applied for Enalapril maleate determination from tablets. The developed and validated method proved to be able to analyze the drug at low concentrations. The main improvement of the validated HPLC method is the relatively low cost of the chemical used. This method can be a good tool to assess the quality control of Enalapril maleate in tablets.

\section{Conflict of interest}

The authors declare no conflict of interest.

\section{References}

[1]. R. de Barros Silva, Hypertension and renin angiotensin system, in: H. Babaei Antihypertensive drugs, InTech, 2012, pp. 85-94. Doi: $10.5772 / 36723$.

[2]. B. Stanisz, Evaluation of stability of enalapril maleate in solid phase, J. Pharm. Biomed. Anal. 21 (2003) 375-380. Doi: 10.1016/S07317085(02)00325-4.

[3]. A. Zoppi, C. Garnero, Y. Garro Linck, A.K. Chattab, G.A. Monti, M.R. Longhi, Enalapril: $\beta$ CD complex: stability enhancement in solid state, Carboh. Polym. 86 (2011) 716-721. Doi: 10.1016/j.carbpol.2011.05.008.

[4]. M.M. Ayad, A.A. Shalaby, H.E. Abdellatef, M.M. Hosny, Spectrophotometric and AAS determination of ramipril and enalapril through ternary complex formation, J. Pharm. Biomed. Anal. 28 (2002) 311-321. Doi: 10.1016/S07317085(01)00595-7.

[5]. S. Gherman, D. Zavastin, A. Spac, V. Dorneanu, Spectrophotometric determination of enalapril using tropeolin 00, Rev. Chim. (Bucharest) 64 (2013) 1224-1228.

[6]. M. Manoranjani, K. Kamala Karuna, UV-visible spectroscopic estimation and validation of enalapril maleate in bulk and pharmaceutical dosage forms, Int. J. Res. Pharm. Biomed. Sci. 2 (2011) 1651-1656.

[7]. N. Rahman, Sk. M. Haque, Optimized and validated spectrophotometric methods for the determination of enalapril maleate in commercial dosage forms, Anal. Chem. Insights. 3 (2008) 31 43. Doi: $10.4137 /$ aci.s643.

[8]. P.S. Patil, H.N. More, Difference spectrophotometric estimation of enalapril maleate from tablet dosage form, Int. J. Res. Pharm. Biomed. Sci. 2 (2011) 629-633.

[9]. S.A. Shama, A.S. Amin, H. Omara, Spectrophotometric microdetermination of some antihypertensive drugs in pure form and in pharmaceutical formulations, J. Chil. Chem. Soc. 56 (2011) 566-570. Doi: 10.4067/S071797072011000100009.

[10]. M. Mohan, S.Z. Haider, A.K. Anand, A.K. Srivastva, Validation of stability indicating HPLC method for the determination of enalapril maleate in tablet formulation, Int. J. Pharm. Pharm. Sci. 3 (2011) 180-183.

[11]. M.Ž. Milenković, P.S. Sibinović, V.D. Marinković, R.M. Palić, G.S. Stojanović, D.M. Milenović, Optimization and validation of an HPLC method for determination of related compounds in enalapril maleate tablets, Anal. Chem. Ind. J. 13 (2013) 135-145.

[12]. L. Logoyda, A.M. Abdel-Megied, Y. Kondratova, O. Trofimenko, D. Korobko, I. Dakhym, Development and validation of HPLC method for the simultaneous determination of enalapril maleate in present of their impurities: application to tablet analysis, Int. J. App. Pharm. 10 (2018) 98102. Doi: 10.22159/ijap.2018v10i1.22805.

[13]. ICH , Validation of Analytical Procedures: Text and Methodology Q2(R1), 2005

[14]. European Pharmacopoeia, Ed. 10, Strasbourg: Council of Europe, 2020.

[15]. A.D. Panainte, M. Vieriu, G. Tantaru, M. Apostu, N. Bibire, L. Avasilcai, I.D. Morariu, RP-HPLC analysis method of bisoprolol fumarate in a new tablet formulation, Med. Surg. J. 122 (2018) 634639.

[16]. G. Tantaru, N. Bibire, A.D. Panainte, M. Vieriu, M. Apostu, Aniline derived bis-Schiff Base analytical reagent for the assay of Fe (III), Rev. Chim. (Bucharest) 69 (2018) 3097-3099.

[17]. T.J. Purohit, Z. Wu, S.M. Hanning, Simple and reliable extraction and a validated high performance liquid chromatographic assay for quantification of amoxicillin from plasma, J. $\begin{array}{llll}\text { Chromatogr. } & \text { A. } 22 & \text { (2019). Doi }\end{array}$ 10.1016/j.chroma.2019.460611.

[18]. A.D. Panainte, L. Agoroaei, N. Bibire, G. Tantaru, M. Apostu, M. Vieriu, A.F. Spac, A HPLC method for the determination of bisoprolol in tablets and its 
application to a bioequivalence study, Rev. Chim. (Bucharest) 66 (2015) 1791-1795.

[19]. K. Konam, J. Soujanya, M. Sasikala, A. Kiran Kumar, Development and validation of RP-HPLC method for the determination of bisoprolol fumarate tablets. Int. J. Res. Pharm. Nano. Sci. 2 (2013) 57-67.
[20]. FDA, Reviewer Guidance, Validation of chromatographic methods, Center for Drug Evaluation and Research (CDER), (1994).

Received: 30.03 .2021

Received in revised form: 03.06.2021

Accepted: 05.06.2021 